\title{
Discrete Switched Model and Fuzzy Robust Control of Dynamic Supply Chain Network
}

\author{
Songtao Zhang $\mathbb{D}^{1},{ }^{1}$ Chunyang Zhang, ${ }^{2}$ Siqi Zhang, ${ }^{3}$ and Min Zhang ${ }^{4}$ \\ ${ }^{1}$ School of Logistics, Linyi University, Linyi 276005, China \\ ${ }^{2}$ School of Management, Harbin University of Commerce, Harbin 150028, China \\ ${ }^{3}$ Faculty of Business and Economics, The University of Melbourne, Melbourne, VIC 3010, Australia \\ ${ }^{4}$ Library, Linyi University, Linyi 276005, China
}

Correspondence should be addressed to Songtao Zhang; zst0626@163.com

Received 17 September 2017; Revised 30 November 2017; Accepted 19 December 2017; Published 16 January 2018

Academic Editor: Roberto Dominguez

Copyright (c) 2018 Songtao Zhang et al. This is an open access article distributed under the Creative Commons Attribution License, which permits unrestricted use, distribution, and reproduction in any medium, provided the original work is properly cited.

\begin{abstract}
Supply chain network is more complex and dynamic under the uncertain demand and the lead time. Robustness is a key index of the stable operation for the supply chain network. We investigate a fuzzy robust strategy to realize the robust operation of the supply chain network with the production lead times and the ordering lead times under the uncertain customer demand. A discrete switched model of the dynamic supply chain network with the lead times and the uncertain customer demand is established based on T-S fuzzy systems. Then a fuzzy switched strategy is proposed to control the switching actions among subsystems. Furthermore, by introducing the inhibition rate $\gamma$, a fuzzy control strategy for the dynamic supply chain network is put forward to suppress the impacts of the lead times and the uncertain customer demand on the operation of the dynamic supply chain network. The fuzzy robust strategy composed of the fuzzy switched strategy and the fuzzy control strategy can guarantee the robust operation of the supply chain network at low cost. Finally, the simulation researches show the advantage of the proposed fuzzy robust strategy through the comparisons with the common robust strategy.
\end{abstract}

\section{Introduction}

As an important management mode, supply chain management is a key factor to enhance the performance of firms in the global marketplace. With the fast changes of global economy and the increasing pressure of market competition, supply chain system has become a complex dynamic network system. The complexity of the supply chain network includes two aspects: on the one hand, the supply chain network consists of numerous economic subjects (such as manufacturers, distributors, and dealers), and there exists a variety of demand and supply relationships among the economic subjects, which form the structural complexity of the supply chain network; on the other hand, the uncertain demand and the lead time in the supply chain network cause the demand forecast to be more difficult, which forms the operational complexity of the supply chain network. For the structural complexity of the supply chain network, there are many research results about mathematical optimization strategies [1-7] and control strategies [8-10].

However, the uncertain demand and the lead time make the supply chain network more dynamic, which will make it more difficult for the supply chain network to achieve smooth operation. For the robustly stable supply chain network with the uncertain demand and the lead time, the system variables (such as inventory) can return to the normal states within a certain amount of time. Conversely, the unstable system will encounter the inventory backlog or serious out of stock phenomena, which will lead to the high operation cost of the system. For example, the operation cost of the supply chain under chaotic state will be more than 500 times higher than that under stable state [11]. Therefore, how to cope with the impacts of the uncertain demand and the lead time on the supply chain network and realize the robustly stable operation of the supply chain network with low cost has received much attention. 
For the supply chain network with the uncertain demand, using a scenario-based approach, Almansoori and Shah [12] presented key strategic and operational decisions on the future hydrogen supply chain network with uncertainty arising from long-term variation in hydrogen demand. Khatami et al. [13] applied Benders' decomposition to solve the stochastic mixed-integer model to optimize the closed-loop supply chain network with the uncertainties of products demand and returned products. For the stochastic demands of a multistage and multiperiod supply chain network, Govindan and Fattahi [14] applied a Latin hypercube sampling method to obtain risk-averse and robust solutions. Utilizing the combination of sample average approximation and Latin hypercube sampling methods, Hamta et al. [15] addressed the optimization of strategic and tactical decisions in the supply chain network design under demand uncertainty. Using a simulation-optimization approach to capture the randomness of the uncertain parameters, Salem and Haouari [16] investigated a three-echelon stochastic supply chain network design problem under the uncertain supply and the demand to minimize the total expected cost. Hamta et al. [17] proposed a scenario generation algorithm to deal with demand uncertainty for the supply chain network design considering assembly line balancing. Constructing a threestage hybrid robust/stochastic program model, Haddadisakht and Ryan [18] optimized the design of a closed-loop supply chain network with uncertainty in demands for both new and returned products.

There are few literature sources on the supply chain network with the lead time. Eskigun et al. [19] modeled the relationship between the lead times and the volume of flow through the nodes of an automotive supply chain network. For companies that implement a Make-to-Order production system in a global supply chain network, Xiao [20] proposed a theory named the Key-Part Based Lead Time Management to reduce nonvalue added waste. In order to deal with the approximate optimal inventory control problem of the supply chain networks with lead time, introducing a sensitivity parameter, Han et al. [21] transformed the original optimal problem into a sequence of two-point boundary value problems without time-delay term.

There are fewer literature sources on the supply chain network with the uncertain demand and the lead time. Li and Liu [22] stated a robust control method to minimize the negative effect of uncertainties in demand, production process, supply chain network structure, inventory policy implementation, and vendor order placement lead time delays. Fattahi et al. [23] exploited the mitigation and contingency strategies for a multiperiod supply chain network with stochastic demands and delivery lead times.

Moreover, the management and control of the inventory is one of the most important subjects in the supply chain network. Because the inventory levels of firms often change, firms will carry out different strategies of production or ordering for the different inventory levels to reduce cost [24]. However, all of the literature sources mentioned above did not consider the different production strategies and ordering strategies for the different inventory levels.
In this article, a dynamic fuzzy model of the supply chain network with the uncertain demand and the lead times is constructed, which involves not only manufacturers' safety inventories and expected inventories, but also distributors' safety inventories and expected inventories. Then, based on the different production strategies and ordering strategies for the different inventory levels, we present a fuzzy switched strategy to suppress the fluctuations of the system variables in switching processes. What is more, we propose a fuzzy control strategy to make the fuzzy supply chain network robustly asymptotically stable in the presence of the lead times and the uncertain customer demand. Finally, simulation experiments are executed to study the impacts of the lead times, the uncertain customer demand, and the fluctuation of the switching processes among subsystems on the supply chain network under the common robust strategy and the proposed fuzzy robust strategy composed of the fuzzy switched strategy and the fuzzy control strategy, respectively.

The rest of this article is organized as follows: In Section 2, a basic dynamic supply chain network system is constructed and then the constructed system is transformed into a fuzzy supply chain network model with the uncertain customer demand and the lead times. In Section 3, we develop a stability theorem of the supply chain network. In Section 4, a simulation example is provided to show the effectiveness of the proposed fuzzy robust strategy for the supply chain network system. In Section 5, discussions are given. Finally, some conclusions are presented in Section 6.

\section{Models of Supply Chain Network}

2.1. Basic Model of Supply Chain Network. The basic notations in models of supply chain network are listed in Notations section.

We consider a type of dynamic supply chain network with a dual-echelon network including $s$ manufacturers and $t$ distributors, and the microstructure of the network in Figure 1 illustrates the structure characteristics of the supply chain network.

In Figure 1, $\mathbf{L}=\left(l_{a b}\right)_{s \times t}\left(0 \leq l_{a b} \leq 1\right)$ is the structure parameter matrix of supply and demand between manufacturers and distributors; if $0<l_{a b} \leq 1$, there is a relationship of supply and demand between manufacturer $a$ and distributor $b$; if $l_{a b}=0$, there is not a relationship of supply and demand between manufacturer $a$ and distributor $b$.

From Figure 1, a basic inventory model of the dynamic supply chain network is constructed as follows:

$$
\begin{aligned}
& x_{a}(k+1)=x_{a}(k)+u_{a}(k)-\sum_{b=1}^{t} l_{a b} u_{a b}(k), \\
& y_{b}(k+1)=y_{b}(k)+\sum_{a=1}^{s} l_{a b} u_{a b}(k)-w_{b}(k) .
\end{aligned}
$$

In supply chain management, lead time is an important indicator to measure the rapid response ability of supply chain for the rapid changes in the market demand. In reality, the lead time is very common in each link of supply chain 


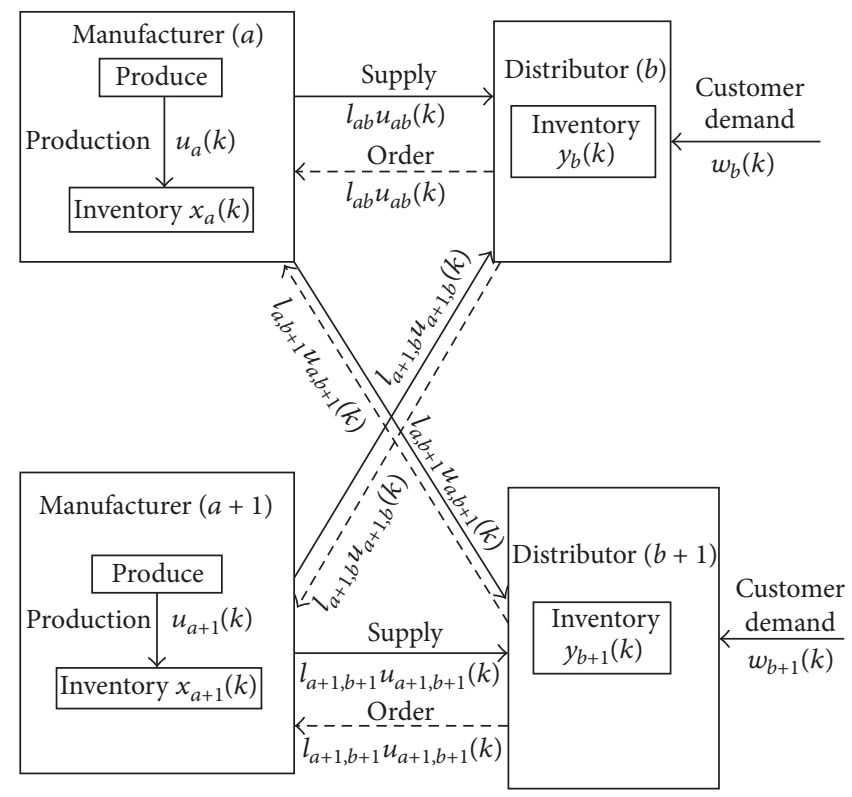

FIGURE 1: Microstructure of supply chain network.

operation, which is influenced by many kinds of economies and technologies. What is more, the lead time not only increases the management cost of firms, but also causes the inefficient operations of the supply chain. Based on (1), a basic model of the supply chain network with the production lead times and the ordering lead times can be described as follows:

$$
\begin{aligned}
x_{a}(k+1)= & x_{a}(k)+u_{a}(k)+u_{a}\left(k-\tau_{a}\right) \\
& -\sum_{b=1}^{t} l_{a b} u_{a b}(k), \\
y_{b}(k+1)= & y_{b}(k)+\sum_{a=1}^{s} l_{a b} u_{a b}(k)+\sum_{a=1}^{s} l_{a b} u_{a b}\left(k-\tau_{a b}\right) \\
& -w_{b}(k) .
\end{aligned}
$$

\subsection{T-S Fuzzy Model of Supply Chain Network with Uncertain} Demand and Lead Times. For the supply chain network with the uncertain demand and the lead times, there are different basic dynamic inventory models at different periods. In order to reduce the cost of the supply chain network effectively, the switching action will often occur among the different basic models. The different switching rules will affect the performance of the supply chain network to different extent. TakagiSugeno (T-S) fuzzy systems, suggested by Takagi and Sugeno in 1985 [25], consist of fuzzy If...Then rules with linguistic terms in antecedents and analytic dynamical equations in the consequents, which can be viewed as the expansion of piecewise linear partition based on "fuzzy partition" of input space [26]. In order to realize the flexible switching among the different basic models and restrain large fluctuations of the system variables in the switching processes, by utilizing T-S fuzzy systems and increasing the cost output equation, under the uncertain customer demand, the discrete T-S fuzzy model of the dynamic supply chain network with the production lead times and the ordering lead times can be described as

$R^{i}:$ if $x_{1}(k)$ is $M_{1}^{i}, \ldots, x_{j}(k)$ is $M_{j}^{i}, \ldots$, and $x_{n}(k)$ is $M_{n}^{i}$, then

$$
\begin{aligned}
\mathbf{x}(k+1)= & \mathbf{A}_{i} \mathbf{x}(k)+\mathbf{B}_{i} \mathbf{u}(k)+\sum_{e=1}^{g} \mathbf{B}_{i e} \mathbf{u}\left(k-\tau_{e}\right) \\
& +\mathbf{B}_{w i} \mathbf{w}(k), \\
z(k)= & \mathbf{C}_{i} \mathbf{x}(k)+\mathbf{D}_{i} \mathbf{u}(k)+\sum_{e=1}^{g} \mathbf{D}_{i e} \mathbf{u}\left(k-\tau_{e}\right), \\
\mathbf{x}(k)= & \boldsymbol{\varphi}(k), \quad k \in\{0,1, \ldots, N\},
\end{aligned}
$$

where $\varphi(k)$ is the initial condition; $\mathbf{x}(k)$ is the inventory state vector at period $k, \mathbf{x}(k)=$ $\left[\begin{array}{llllllllll}x_{1}(k) & \cdots & x_{a}(k) & \cdots & x_{s}(k) & y_{1}(k) & \cdots & y_{b}(k) & \cdots & y_{t}(k)\end{array}\right]^{T}$; $\mathbf{u}(k)$ is the production and ordering control vector at period $k ; \mathbf{u}\left(k-\tau_{e}\right)$ is the production and ordering control vector with lead times at period $k ; e=1, \ldots, a, \ldots, s, 11, \ldots, a b, \ldots s t$; $g=s+s t ; \mathbf{w}(k)$ is the customer demand vector at period $k$, which is assumed to belong to $l_{2}[0, \infty)$. $\mathbf{A}_{i}=\left[\begin{array}{cccc}1 & & & \\ & 1 & \ddots & \\ & & \ddots & \\ & & \end{array}\right]_{(s+t) \times(s+t)}$ is the inventory status coefficient matrix, which embodies the inventory level of the supply

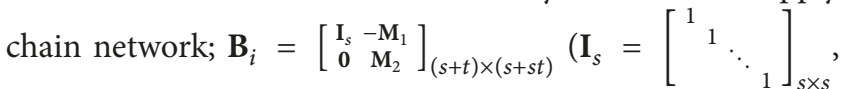
$\mathbf{M}_{1}=\left[\begin{array}{ccccc}\mathbf{L}_{1} & & & & \\ & \ddots & & \\ & & \mathbf{L}_{a} & \\ & & \ddots & \\ & & & \mathbf{L}_{s}\end{array}\right]_{s \times s t}, \mathbf{L}_{a}=\left[\begin{array}{lllll}l_{a 1} & \cdots & l_{a b} & \cdots & l_{a t}\end{array}\right]_{1 \times t}, \mathbf{M}_{2}=$ $\left.\left[\begin{array}{lllll}\mathbf{H}_{1} & \cdots & \mathbf{H}_{a} & \cdots & \mathbf{H}_{s}\end{array}\right]_{t \times t s}, \mathbf{H}_{a}=\left[\begin{array}{llll}l_{a 1} & & & \\ & \ddots & & \\ & & l_{a b} & \\ & & \ddots & \\ & & & l_{a t}\end{array}\right]_{t \times t}\right)$ is the 
production or ordering coefficient matrix, which embodies manufacturers' production capacity or distributors' ordering quantity; for the production delay coefficient matrix caused by lead time, $\mathbf{B}_{i e}=\left[\begin{array}{cc}\mathbf{I}_{s} & \mathbf{0} \\ \mathbf{0} & \mathbf{0}\end{array}\right]_{(s+t) \times(s+s t)}$; for the ordering delay coefficient matrix caused by lead time, $\mathbf{B}_{i e}=\left[\begin{array}{cc}\mathbf{0} & \mathbf{0} \\ \mathbf{0} & \mathbf{M}_{2}\end{array}\right]_{(s+t) \times(s+s t)}$; $\mathbf{B}_{w i}=\left[\begin{array}{c}0 \\ -\mathbf{I}\end{array}\right]_{(s+t) \times(s+t)}$ is the customer demand coefficient matrix; $\mathbf{C}_{i}=\left[\begin{array}{llllllllll}c_{h 1} & \cdots & c_{h a} & \cdots & c_{h s} & c_{r 1} & \cdots & c_{r b} & \cdots & c_{r t}\end{array}\right]_{1 \times(s+t)}$ is the inventory cost coefficient matrix; $\mathbf{D}_{i}=$ $\left[\begin{array}{llllllllll}c_{m 1} & \cdots & c_{m a} & \cdots & c_{m s} & \mathbf{c}_{o 1} & \cdots & \mathbf{c}_{o a} & \cdots & \mathbf{c}_{o s}\end{array}\right]_{1 \times(s+s t)}$ is the cost coefficient matrix of the production and ordering, where $c_{o a}$ is distributors' unit ordering cost matrix from manufacturer $a\left(\mathbf{c}_{o a}=\left[\begin{array}{lllll}l_{a 1} c_{o a 1} & \cdots & l_{a b} c_{o a b} & \cdots & l_{a t} c_{o a t}\end{array}\right]\right)$; for the cost coefficient matrix of production with lead times, $\mathbf{D}_{i e}=\left[\begin{array}{llllll}c_{m 1} & \cdots & c_{m a} & \cdots & c_{m s} & \mathbf{0}\end{array}\right]_{1 \times(s+s t)}$; for the cost coefficient matrix of ordering with lead times, $\mathbf{D}_{i e}=\left[\begin{array}{llllll}\mathbf{0} & \mathbf{c}_{o 1} & \cdots & \mathbf{c}_{o a} & \cdots & \mathbf{c}_{o s}\end{array}\right]_{1 \times(s+s t)}$.

In this article, the fuzzy supply chain network system (3) is described by deviation variables, which are the differences between the actual operation values and the nominal values.

By singleton fuzzifier, product inference, and centreaverage defuzzifier, the fuzzy supply chain network system (3) is inferred as follows:

$$
\begin{aligned}
& \mathbf{x}(k+1)=\sum_{i=1}^{r} h_{i}(\mathbf{x}(k)) \\
& \cdot\left[\mathbf{A}_{i} \mathbf{x}(k)+\mathbf{B}_{i} \mathbf{u}(k)+\sum_{e=1}^{g} \mathbf{B}_{i e} \mathbf{u}\left(k-\tau_{e}\right)+\mathbf{B}_{w i} \mathbf{w}(k)\right], \\
& z(k)=\sum_{i=1}^{r} h_{i}(\mathbf{x}(k)) \\
& .\left[\mathbf{C}_{i} \mathbf{x}(k)+\mathbf{D}_{i} \mathbf{u}(k)+\sum_{e=1}^{g} \mathbf{D}_{i e} \mathbf{u}\left(k-\tau_{e}\right)\right]
\end{aligned}
$$

where $h_{i}(\mathbf{x}(k))=\mu_{i}(\mathbf{x}(k)) / \sum_{i=1}^{r} \mu_{i}(\mathbf{x}(k)), \mu_{i}(\mathbf{x}(k))=$ $\prod_{j=1}^{n} M_{j}^{i}\left(x_{j}(k)\right), M_{j}^{i}\left(x_{j}(k)\right)$ is the grade of membership of $x_{j}(k)$ in the fuzzy set $M_{j}^{i}, \mu_{i}(\mathbf{x}(k))$ is the membership degree of the $i$ th rule. For simplicity, we omit $\mathbf{x}(k)$ in $h_{i}(\mathbf{x}(k))$.

\section{Fuzzy Robust Strategy of Dynamic Supply Chain Network}

3.1. Inhibition Rate of Fuzzy Robust Controller. Fuzzy robust control can effectively help firms to cope with the operational lead times and the uncertain customer demand and guarantee the asymptotic stability of the supply chain network. We use the parameter $\gamma$ as the inhibition rate of the fuzzy robust controller; namely,

$$
\frac{\left\|\sum_{i=1}^{r} \sum_{j=1}^{r} h_{i} h_{j}\left[\left(\mathbf{C}_{i}-\mathbf{D}_{i} \mathbf{K}_{j}\right) \mathbf{x}(k)-\sum_{e=1}^{g} \mathbf{D}_{i e} \mathbf{K}_{j e} \mathbf{x}\left(k-\tau_{e}\right)\right]\right\|_{2}}{\|\mathbf{w}(k)\|_{2}}
$$

$$
\leq \gamma
$$

where $\|\cdot\|_{2}$ is $l_{2} \in[0, \infty)$ norm. Inequality (5) describes the system gain characteristic from the uncertain customer demand variable $\mathbf{w}(k)$ to the total cost $z(k)$ of the supply chain network; namely, the smaller the parameter $\gamma$ is, the better the performance of the supply chain network system will be, and the fuzzy robust strategy can make inequality (5) achieve the ideal value.

\subsection{Fuzzy Control Strategy for Discrete Switched Supply Chain} Network. Based on the principle of the parallel distributed compensation, the design of a fuzzy controller is to synthesize a local feedback controller for each subsystem. Then the local state feedback controller is formulated as follows:

controller rule $K^{i}$ : if $x_{1}(k)$ is $M_{1}^{i}, \ldots, x_{j}(k)$ is $M_{j}^{i}, \ldots$, and $x_{n}(k)$ is $M_{n}^{i}$, then

$$
\begin{aligned}
\mathbf{u}(k) & =-\mathbf{K}_{i} \mathbf{x}(k), \\
\mathbf{u}\left(k-\tau_{e}\right) & =-\mathbf{K}_{i e} \mathbf{x}\left(k-\tau_{e}\right),
\end{aligned}
$$

where $\mathbf{K}_{i}$ and $\mathbf{K}_{i e}$ are the state feedback gain matrix and the state feedback gain matrix with the lead times, respectively.

The state feedback controller of the global supply chain network can be expressed as

$$
\begin{gathered}
\mathbf{u}(k)=-\sum_{i=1}^{r} h_{i} \mathbf{K}_{i} \mathbf{x}(k), \\
\mathbf{u}\left(k-\tau_{e}\right)=-\sum_{i=1}^{r} h_{i} \mathbf{K}_{i e} \mathbf{x}\left(k-\tau_{e}\right) .
\end{gathered}
$$

Then the fuzzy control system of the supply chain network can be written as

$$
\begin{aligned}
& \mathbf{x}(k+1)=\sum_{i=1}^{r} \sum_{j=1}^{r} h_{i} h_{j} \cdot\left[\left(\mathbf{A}_{i}-\mathbf{B}_{i} \mathbf{K}_{j}\right) \mathbf{x}(k)\right. \\
& \left.-\sum_{e=1}^{g} \mathbf{B}_{i e} \mathbf{K}_{j e} \mathbf{x}\left(k-\tau_{e}\right)+\mathbf{B}_{w i} \mathbf{w}(k)\right] \\
& z(k)=\sum_{i=1}^{r} \sum_{j=1}^{r} h_{i} h_{j} \cdot\left[\left(\mathbf{C}_{i}-\mathbf{D}_{i} \mathbf{K}_{j}\right) \mathbf{x}(k)\right. \\
& \left.\quad-\sum_{e=1}^{g} \mathbf{D}_{i e} \mathbf{K}_{j e} \mathbf{x}\left(k-\tau_{e}\right)\right]
\end{aligned}
$$

Before further analysis, we introduce the following definitions as the preparation for Theorem 3 .

Definition 1 (see [27]). A cluster of fuzzy sets $\left\{F_{j}^{u}, u=\right.$ $\left.1,2, \ldots, q_{j}\right\}$ are said to be a standard fuzzy partition (SFP) in the universe $X$ if each $F_{j}^{u}$ is a normal fuzzy set and $F_{j}^{u}(u=$ $1,2, \ldots, q_{j}$ ) are full-overlapped in the universe $X . q_{j}$ is said to be the number of fuzzy partitions of the $j$ th input variable on $X$.

Definition 2 (see [27]). For a given fuzzy system, an overlapped-rules group with the largest amount of rules is said to be a maximal overlapped-rules group (MORG). 
The stability theorem of the supply chain network will be given in the form of Theorem 3 .

Theorem 3. For the fuzzy supply chain network system (8) with lead times and SFP inputs, if there exist a given scalar $\gamma>0$, local common positive definite matrices $\mathbf{P}_{c}$ and $\mathbf{Q}_{e c}$, and matrices $\mathbf{K}_{i c}, \mathbf{K}_{j c}, \mathbf{K}_{i e c}, \mathbf{K}_{j e c}$ in $\mathbf{G}_{c}$ satisfying

$$
\left[\begin{array}{ccccc}
-\mathbf{P}_{c}+\sum_{e=1}^{g} \mathbf{Q}_{e c} & * & * & * & * \\
\mathbf{0} & -\widehat{\mathbf{Q}} & * & * & * \\
\mathbf{0} & \mathbf{0} & -\gamma^{2} \mathbf{I} & * & * \\
\mathbf{A}_{i}-\mathbf{B}_{i} \mathbf{K}_{i c} & -\Pi_{1} & \mathbf{B}_{w i} & -\mathbf{P}_{c} & * \\
\mathbf{C}_{i}-\mathbf{D}_{i} \mathbf{K}_{i c} & -\Pi_{2} & \mathbf{0} & \mathbf{0} & -\mathbf{I}
\end{array}\right]<\mathbf{0}, \quad i \in I_{\mathfrak{c}}
$$

$$
\begin{aligned}
& {\left[\begin{array}{ccccc}
-4 \mathbf{P}_{c}+4 \sum_{e=1}^{g} \mathbf{Q}_{e c} & * & * & * & * \\
\mathbf{0} & -4 \widehat{\mathbf{Q}} & * & * & * \\
\mathbf{0} & \mathbf{0} & -4 \gamma^{2} \mathbf{I} & * & * \\
\mathbf{A}_{i}-\mathbf{B}_{i} \mathbf{K}_{j c}+\mathbf{A}_{j}-\mathbf{B}_{j} \mathbf{K}_{i c} & -\boldsymbol{\Phi}_{1} & \mathbf{B}_{w i}+\mathbf{B}_{w j} & -\mathbf{P}_{c} & * \\
\mathbf{C}_{i}-\mathbf{D}_{i} \mathbf{K}_{j c}+\mathbf{C}_{j}-\mathbf{D}_{j} \mathbf{K}_{i c} & -\mathbf{\Phi}_{2} & \mathbf{0} & \mathbf{0} & -\mathbf{I}
\end{array}\right]} \\
& <\mathbf{0}, \quad i<j, i, j \in I_{c},
\end{aligned}
$$

then the fuzzy supply chain network system (8) is robustly asymptotically stable under the performance $\gamma$, where $I_{c}$ is the set of the rule numbers included in $\mathbf{G}_{c}, \mathbf{G}_{c}$ denotes the cth $M O R G, c=1,2, \ldots, \prod_{j=1}^{n}\left(m_{j}-1\right), m_{j}$ is the number of the fuzzy partitions of the jth input variable, $\widehat{\mathbf{Q}}=$ $\operatorname{diag}\left\{\begin{array}{lllll}\mathbf{Q}_{1 c} & \cdots & \mathbf{Q}_{e c} & \cdots & \mathbf{Q}_{g c}\end{array}\right\}$,

$$
\begin{aligned}
& \Pi_{1}=\left[\begin{array}{lllll}
\mathbf{B}_{i 1} \mathbf{K}_{i 1 c} & \cdots & \mathbf{B}_{i e} \mathbf{K}_{i e c} & \cdots & \mathbf{B}_{i g} \mathbf{K}_{i g c}
\end{array}\right], \\
& \boldsymbol{\Pi}_{2}=\left[\begin{array}{lllll}
\mathbf{D}_{i 1} \mathbf{K}_{i 1 c} & \cdots & \mathbf{D}_{i e} \mathbf{K}_{i e c} & \cdots & \mathbf{D}_{i g} \mathbf{K}_{i g c}
\end{array}\right], \\
& \boldsymbol{\Phi}_{1}=\left[\begin{array}{lllll}
\mathbf{B}_{i 1} \mathbf{K}_{j 1 c}+\mathbf{B}_{j 1} \mathbf{K}_{i 1 c} & \cdots & \mathbf{B}_{i e} \mathbf{K}_{j e c}+\mathbf{B}_{j e} \mathbf{K}_{i e c} & \cdots & \mathbf{B}_{i g} \mathbf{K}_{j g c}+\mathbf{B}_{j g} \mathbf{K}_{i g c}
\end{array}\right], \\
& \boldsymbol{\Phi}_{2}=\left[\begin{array}{lllll}
\mathbf{D}_{i 1} \mathbf{K}_{j 1 c}+\mathbf{D}_{j 1} \mathbf{K}_{i 1 c} & \cdots & \mathbf{D}_{i e} \mathbf{K}_{j e c}+\mathbf{D}_{j e} \mathbf{K}_{i e c} & \cdots & \mathbf{D}_{i g} \mathbf{K}_{j g c}+\mathbf{D}_{j g} \mathbf{K}_{i g c}
\end{array}\right] .
\end{aligned}
$$

Proof. The proof processes of Theorem 3 in this paper are similar to those of Theorems 1 and 2 in [28], which are omitted for the sake of brevity.

For the supply chain network with the uncertain customer demand and the lead times, we propose the following fuzzy robust strategy, which consists of the fuzzy switched strategy and the fuzzy control strategy.

(1) Fuzzy switched strategy

(1) When a manufacturer's inventory is less than the safety inventory, the manufacturer will urgently produce the goods; If a manufacturer's inventory is more than the safety inventory and less than the expected inventory, the manufacture will normally produce the goods; If a manufacturer's inventory is more than the expected inventory, the manufacture will stop producing.

(2) When a distributor's inventory is less than the safety inventory, the distributor will urgently order the goods; If a distributor's inventory is more than the safety inventory and less than the expected inventory, the distributor will normally order the goods; If a distributor's inventory is more than the expected inventory, the distributor will stop ordering.

(3) According to (4), when the manufacturers and the distributors lie in different inventories, there are the different fuzzy control rules. When manufactures' inventories and distributors' inventories change, the switching actions will occur among fuzzy control rules. Due to the fuzzy membership function, the switching actions can be seen as a flexible switching, which is also called a robust switching.

(2) Fuzzy control strategy
(1) If a proper inhibition rate $\gamma$ is given, by solving (9), we can obtain the state feedback gain matrices. The closedloop negative feedback control can be realized by using state feedback controller (7). Then all variables in the fuzzy supply chain network (8) can realize robust stabilization under the uncertain demand and the lead times.

(2) The optimal inhibition rate $\gamma$ can be obtained according to Figure 2.

\section{Simulation Research}

4.1. Modeling Supply Chain Network with 2 Manufacturers and 2 Distributors. In practice, material processing and material acquisition of steel industry are very complicated processes because there are so many upstream and downstream members, materials, and semifinished products. To assess the performance of the designed fuzzy robust strategy and to gain further insights into the dynamical characteristics of the supply chain network with the lead times under the uncertain customer demand, we choose an H-beam supply chain network of North Tai Steel Group in China as a simulation object. And this supply chain network consists of 2 manufacturers and 2 distributors.

In this section, according to the inventory levels, manufacturers will develop the production strategy to avoid the inventory backlog or increase opportunity cost; at the same time, according to manufacturers' inventory levels, distributors will formulate the ordering strategy. Thus, the 


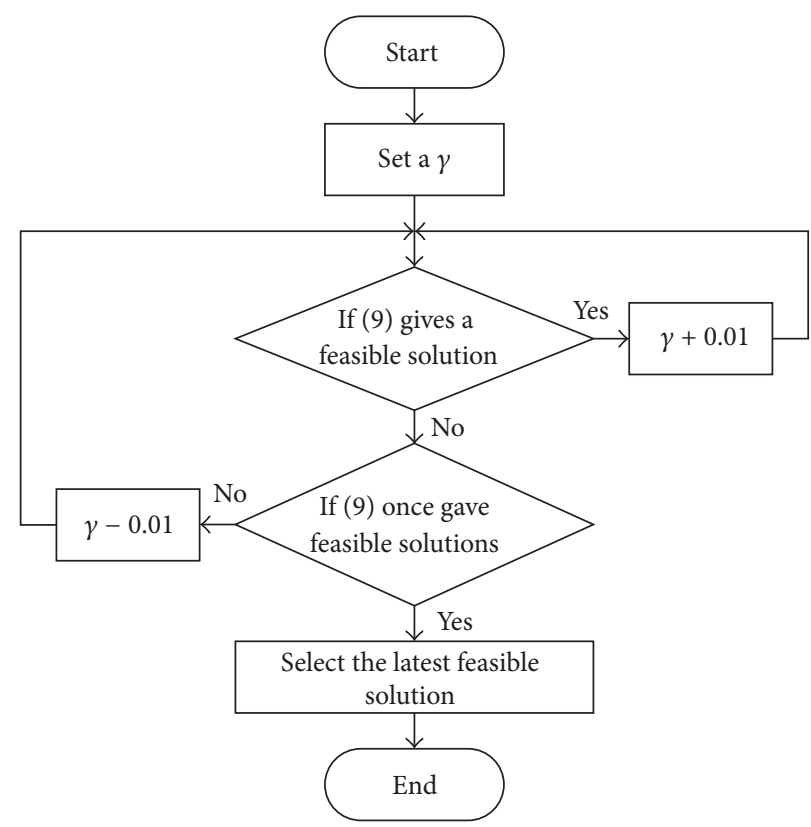

FIGURE 2: Flow chart of selecting the optimal inhibition rate.

dynamic model of the supply chain network with the lead times is established at period $k$ as follows:

$$
\begin{aligned}
& x_{1}(k+1)= x_{1}(k)+u_{1}(k)+u_{1}\left(k-\tau_{1}\right)-l_{11} u_{11}(k) \\
&-l_{12} u_{12}(k), \\
& x_{2}(k+1)= x_{2}(k)+u_{2}(k)+u_{2}\left(k-\tau_{2}\right)-l_{21} u_{21}(k) \\
&-l_{22} u_{22}(k), \\
& y_{1}(k+1)=y_{1}(k)+l_{11} u_{11}(k)+l_{11} u_{11}\left(k-\tau_{11}\right) \\
&+l_{21} u_{21}(k)+l_{21} u_{21}\left(k-\tau_{21}\right) \\
&-w_{1}(k), \\
& y_{2}(k+1)= y_{2}(k)+l_{12} u_{12}(k)+l_{12} u_{12}\left(k-\tau_{12}\right) \\
&+l_{22} u_{22}(k)+l_{22} u_{22}\left(k-\tau_{22}\right) \\
&-w_{2}(k),
\end{aligned}
$$

where $x_{1}(k), x_{2}(k), y_{1}(k)$, and $y_{2}(k)$ are manufacturer l's inventory, manufacturer 2's inventory, distributor l's inventory, and distributor 2's inventory of the supply chain network at period $k$, respectively, which are state variables. $u_{1}(k)$, $u_{2}(k), u_{11}(k), u_{12}(k), u_{21}(k)$, and $u_{22}(k)$ are manufacturer 1's production, manufacturer 2's production, distributer l's ordering quantity from manufacturer 1, distributor 2's ordering quantity from manufacturer 1, distributor 1's ordering quantity from manufacturer 2, and distributor 2's ordering quantity from manufacturer 2 , respectively, which are the control variables. $u_{1}\left(k-\tau_{1}\right)$ and $u_{2}\left(k-\tau_{2}\right)$ are the productions with lead times $\tau_{1}$ and $\tau_{2} ; u_{11}\left(k-\tau_{11}\right), u_{12}\left(k-\tau_{12}\right), u_{21}\left(k-\tau_{21}\right)$, and $u_{22}\left(k-\tau_{22}\right)$ are the ordering quantities with lead times $\tau_{11}, \tau_{12}, \tau_{21}$, and $\tau_{22}$, in which $\tau_{e}(e=1,2,11,12,21,22)$ is

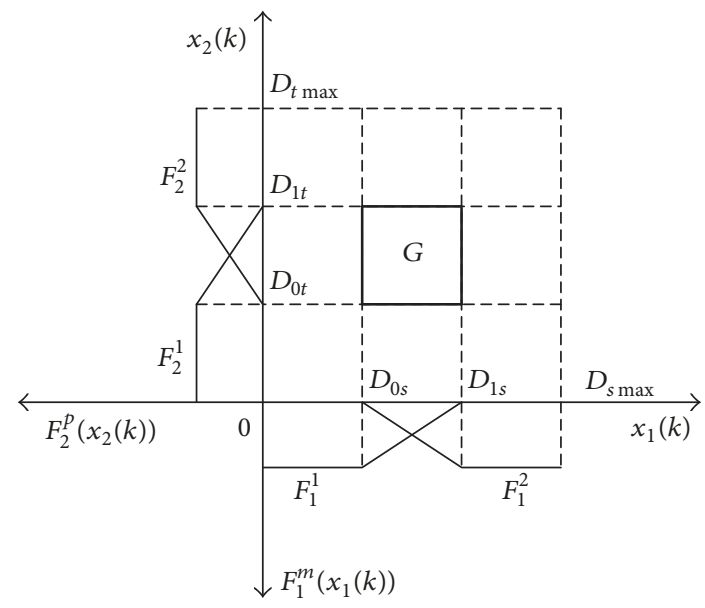

FIgURE 3: Fuzzy membership functions.

independent lead time parameter. Let $\tau^{\prime}=\tau_{1}=\tau_{2}$ and $\tau^{\prime \prime}=\tau_{11}=\tau_{12}=\tau_{21}=\tau_{22} \cdot w_{1}(k)$ and $w_{2}(k)$ are the customer demand at period $k$, which are uncertain variables. $l_{11}, l_{12}, l_{21}$, and $l_{22}$ are the ordering rates.

Suppose $x_{1}(k)$ and $x_{2}(k)$ can be measured, the fuzzy partitions of $x_{1}(k)$ and $x_{2}(k)$ are $F_{1}^{m}\left(x_{1}(k)\right)(m=1,2)$ and $F_{2}^{p}\left(x_{2}(k)\right)(p=1,2)$, respectively, and conform to the conditions of SFP. Let $M_{1}^{1}=M_{1}^{2}=F_{1}^{1}, M_{1}^{3}=$ $M_{1}^{4}=F_{1}^{2}, M_{2}^{1}=M_{2}^{3}=F_{2}^{1}, M_{2}^{2}=M_{2}^{4}=F_{2}^{2}$. The fuzzy sets of $x_{1}(k)$ and $x_{2}(k)$ represented by the membership functions are shown in Figure $3\left(D_{0 s}, D_{1 s}\right.$, and $D_{s \max }$ are manufacturer l's safety inventory, expected inventory, and maximum inventory, respectively; $D_{0 t}, D_{1 t}$, and $D_{t \max }$ are manufacturer 2's safety inventory, expected inventory, and maximum inventory, respectively). 
In Figure 3, we can see that there exists a MORG containing 4 fuzzy rules. According to Theorem 3, by considering the lead times, the production capacity, the supply chain structure, and the uncertain customer demand, the twoechelon supply chain network model can be transformed into the following fuzzy model:

$$
\begin{aligned}
& R^{i} \text { : if } x_{1}(k) \text { is } M_{1}^{i} \text { and } x_{2}(k) \text { is } M_{2}^{i} \text {, then } \\
& \begin{array}{l}
\mathbf{x}(k+1)=\sum_{i=1}^{r} h_{i}\left[\mathbf{A}_{i} \mathbf{x}(k)+\mathbf{B}_{i} \mathbf{u}(k)+\mathbf{B}_{i 1} \mathbf{u}\left(k-\tau^{\prime}\right)\right. \\
\left.\quad+\mathbf{B}_{i 2} \mathbf{u}\left(k-\tau^{\prime \prime}\right)+\mathbf{B}_{w i} \mathbf{w}(k)\right], \\
z(k)=\sum_{i=1}^{r} h_{i}\left[\mathbf{C}_{i} \mathbf{x}(k)+\mathbf{D}_{i} \mathbf{u}(k)+\mathbf{D}_{i 1} \mathbf{u}\left(k-\tau^{\prime}\right)\right. \\
\left.\quad+\mathbf{D}_{i 2} \mathbf{u}\left(k-\tau^{\prime \prime}\right)\right]
\end{array}
\end{aligned}
$$

where $r=4, \mathbf{x}^{T}(k)=\left[\begin{array}{llll}x_{1}(k) & x_{2}(k) & y_{1}(k) & y_{2}(k)\end{array}\right], \mathbf{u}^{T}(k)=$ $\left[\begin{array}{lllllll}u_{1}(k) & u_{2}(k) & u_{11}(k) & u_{12}(k) & u_{21}(k) & u_{22}(k)\end{array}\right]$.

Based on historical data, $l_{a b}$ will be assigned different values for different fuzzy rules: when $i=1, l_{11}=l_{12}=l_{21}=$ $l_{22}=0.5$; when $i=2, l_{11}=0.35, l_{12}=0.43, l_{21}=0.65$, and $l_{22}=0.57$; when $i=3, l_{11}=0.65, l_{12}=0.57, l_{21}=0.35$, and $l_{22}=0.43$; when $i=4, l_{11}=l_{12}=l_{21}=l_{22}=0.5$. Therefore, we have

$$
\begin{aligned}
\mathbf{A}_{1} & =\mathbf{A}_{2}=\mathbf{A}_{3}=\mathbf{A}_{4}=\left[\begin{array}{llll}
1 & 0 & 0 & 0 \\
0 & 1 & 0 & 0 \\
0 & 0 & 1 & 0 \\
0 & 0 & 0 & 1
\end{array}\right], \\
\mathbf{B}_{1} & =\left[\begin{array}{cccccc}
1 & 0 & -0.5 & -0.5 & 0 & 0 \\
0 & 1 & 0 & 0 & -0.5 & -0.5 \\
0 & 0 & 0.5 & 0 & 0.5 & 0 \\
0 & 0 & 0 & 0.5 & 0 & 0.5
\end{array}\right], \\
\mathbf{B}_{2} & =\left[\begin{array}{cccccc}
1 & 0 & -0.35 & -0.43 & 0 & 0 \\
0 & 1 & 0 & 0 & -0.65 & -0.57 \\
0 & 0 & 0.35 & 0 & 0.65 & 0 \\
0 & 0 & 0 & 0.43 & 0 & 0.57
\end{array}\right], \\
\mathbf{B}_{3} & =\left[\begin{array}{cccccc}
1 & 0 & -0.65 & -0.57 & 0 & 0 \\
0 & 1 & 0 & 0 & -0.35 & -0.43 \\
0 & 0 & 0.65 & 0 & 0.35 & 0 \\
0 & 0 & 0 & 0.57 & 0 & 0.43
\end{array}\right], \\
\mathbf{B}_{4}= & {\left[\begin{array}{llcccc}
1 & 0 & -0.5 & -0.5 & 0 & 0 \\
0 & 1 & 0 & 0 & -0.5 & -0.5 \\
0 & 0 & 0.5 & 0 & 0.5 & 0 \\
0 & 0 & 0 & 0.5 & 0 & 0.5
\end{array}\right], }
\end{aligned}
$$

$$
\mathbf{B}_{11}=\mathbf{B}_{21}=\mathbf{B}_{31}=\mathbf{B}_{41}=\left[\begin{array}{llllll}
1 & 0 & 0 & 0 & 0 & 0 \\
0 & 1 & 0 & 0 & 0 & 0 \\
0 & 0 & 0 & 0 & 0 & 0 \\
0 & 0 & 0 & 0 & 0 & 0
\end{array}\right] \text {, }
$$$$
\mathbf{B}_{12}=\left[\begin{array}{cccccc}
0 & 0 & 0 & 0 & 0 & 0 \\
0 & 0 & 0 & 0 & 0 & 0 \\
0 & 0 & 0.5 & 0 & 0.5 & 0 \\
0 & 0 & 0 & 0.5 & 0 & 0.5
\end{array}\right] \text {, }
$$$$
\mathbf{B}_{22}=\left[\begin{array}{cccccc}
0 & 0 & 0 & 0 & 0 & 0 \\
0 & 0 & 0 & 0 & 0 & 0 \\
0 & 0 & 0.35 & 0 & 0.65 & 0 \\
0 & 0 & 0 & 0.43 & 0 & 0.57
\end{array}\right],
$$$$
\mathbf{B}_{32}=\left[\begin{array}{cccccc}
0 & 0 & 0 & 0 & 0 & 0 \\
0 & 0 & 0 & 0 & 0 & 0 \\
0 & 0 & 0.65 & 0 & 0.35 & 0 \\
0 & 0 & 0 & 0.57 & 0 & 0.43
\end{array}\right],
$$$$
\mathbf{B}_{42}=\left[\begin{array}{cccccc}
0 & 0 & 0 & 0 & 0 & 0 \\
0 & 0 & 0 & 0 & 0 & 0 \\
0 & 0 & 0.5 & 0 & 0.5 & 0 \\
0 & 0 & 0 & 0.5 & 0 & 0.5
\end{array}\right] \text {, }
$$

$\mathbf{B}_{w 1}=\mathbf{B}_{w 2}=\mathbf{B}_{w 3}=\mathbf{B}_{w 4}=\left[\begin{array}{cccc}0 & 0 & 0 & 0 \\ 0 & 0 & 0 & 0 \\ 0 & 0 & -1 & 0 \\ 0 & 0 & 0 & -1\end{array}\right]$,

$\mathbf{C}_{1}=\mathbf{C}_{2}=\mathbf{C}_{3}=\mathbf{C}_{4}=\left[\begin{array}{llll}c_{h 1} & c_{h 2} & c_{r 1} & c_{r 2}\end{array}\right]$,

$\mathbf{D}_{1}=\left[\begin{array}{llllll}c_{m J 1} & c_{m J 2} & 0.5 c_{o 11} & 0.5 c_{o 12} & 0.5 c_{o 21} & 0.5 c_{o 22}\end{array}\right]$,

$\mathbf{D}_{2}$

$=\left[\begin{array}{llllll}c_{m J 1} & c_{m N 2} & 0.35 c_{o 11} & 0.43 c_{o 12} & 0.65 c_{o 21} & 0.57 c_{o 22}\end{array}\right]$,

$\mathbf{D}_{3}$

$$
\begin{aligned}
= & {\left[\begin{array}{llllll}
c_{m N 1} & c_{m J 2} & 0.65 c_{o 11} & 0.57 c_{o 12} & 0.35 c_{o 21} & 0.43 c_{o 22}
\end{array}\right], } \\
\mathbf{D}_{4} & =\left[\begin{array}{llllll}
c_{m N 1} & c_{m N 2} & 0.5 c_{o 11} & 0.5 c_{o 12} & 0.5 c_{o 21} & 0.5 c_{o 22}
\end{array}\right], \\
\mathbf{D}_{11} & =\left[\begin{array}{llllll}
c_{m J 1} & c_{m J 2} & 0 & 0 & 0 & 0
\end{array}\right], \\
\mathbf{D}_{21} & =\left[\begin{array}{llllll}
c_{m J 1} & c_{m N 2} & 0 & 0 & 0 & 0
\end{array}\right], \\
\mathbf{D}_{31} & =\left[\begin{array}{llllll}
c_{m N 1} & c_{m J 2} & 0 & 0 & 0 & 0
\end{array}\right], \\
\mathbf{D}_{41} & =\left[\begin{array}{llllll}
c_{m N 1} & c_{m N 2} & 0 & 0 & 0 & 0
\end{array}\right], \\
\mathbf{D}_{12} & =\left[\begin{array}{llllll}
0 & 0 & 0.5 c_{o 11} & 0.5 c_{o 12} & 0.5 c_{o 21} & 0.5 c_{o 22}
\end{array}\right], \\
\mathbf{D}_{22} & =\left[\begin{array}{llllll}
0 & 0 & 0.35 c_{o 11} & 0.43 c_{o 12} & 0.65 c_{o 21} & 0.57 c_{o 22}
\end{array}\right],
\end{aligned}
$$




$$
\begin{aligned}
& \mathbf{D}_{32}=\left[\begin{array}{llllll}
0 & 0 & 0.65 c_{o 11} & 0.57 c_{o 12} & 0.35 c_{o 21} & 0.43 c_{o 22}
\end{array}\right], \\
& \mathbf{D}_{42}=\left[\begin{array}{llllll}
0 & 0 & 0.5 c_{o 11} & 0.5 c_{o 12} & 0.5 c_{o 21} & 0.5 c_{o 22}
\end{array}\right] .
\end{aligned}
$$

We define that $c_{h 1}, c_{h 2}, c_{r 1}$, and $c_{r 2}$ are manufacturer 1's unit inventory cost, manufacturer 2's unit inventory cost, distributor 1's unit inventory cost, and distributor 2's unit inventory cost, respectively; $c_{m 1}=c_{m N 1}$ and $c_{m 2}=c_{m N 2}$ are the manufacturer 1's unit manufacturing costs and the manufacturer 2's unit manufacturing costs under the normal production condition, respectively; $c_{m 1}=c_{m J 1}$ and $c_{m 2}=c_{m J 2}$ are manufacturer 1's unit inventory costs and manufacturer 2's unit inventory costs under the JIT condition, respectively; $c_{o 11}, c_{012}, c_{021}$, and $c_{o 22}$ are distributor 1's unit ordering cost from manufacturer 1, distributor 2's unit ordering cost from manufacturer 1, distributor 1's unit ordering cost from manufacturer 2, and distributor 2's unit ordering cost from manufacturer 2 , respectively.

Then, according to the established T-S fuzzy model, the relative fuzzy state feedback controller of the supply chain network is designed as follows:

$$
K^{i} \text { : if } x_{1}(k) \text { is } M_{1}^{i} \text { and } x_{2}(k) \text { is } M_{2}^{i} \text {, then }
$$

$$
\begin{gathered}
\mathbf{u}(k)=-\sum_{i=1}^{r} h_{i} \mathbf{K}_{i 1} \mathbf{x}(k), \\
\mathbf{u}\left(k-\tau^{\prime}\right)=-\sum_{i=1}^{r} h_{i} \mathbf{K}_{i 11} \mathbf{x}\left(k-\tau^{\prime}\right), \\
\mathbf{u}\left(k-\tau^{\prime \prime}\right)=-\sum_{i=1}^{r} h_{i} \mathbf{K}_{i 21} \mathbf{x}\left(k-\tau^{\prime \prime}\right) .
\end{gathered}
$$

Base on the practices, all parameters of the model are set as $c_{h 1}=1.3, c_{h 2}=1.45, c_{r 1}=0.95, c_{r 2}=1, c_{m N 1}=2.3$, $c_{m J 1}=3, c_{m N 2}=2.1, c_{m J 2}=2.63, c_{o 11}=3.6, c_{o 12}=4.2$, $c_{o 21}=3.95, c_{o 22}=3.81\left(10^{4} \mathrm{RMB} /\right.$ ton $), D_{0 s}=10, D_{1 s}=30$, $D_{0 t}=8, D_{1 t}=33$ (10 $10^{5}$ ton).

4.2. Simulation Analysis. Let the uncertain inhibition parameter $\gamma=1.02$, and the fuzzy supply chain network system (12) is robustly stable because the corresponding results that meet Theorem 3 can be obtained by using the feasp solver in LMI Toolbox of Matlab as follows:

$$
\begin{aligned}
\mathbf{P}_{1} & =\left[\begin{array}{cccc}
31.5151 & 0.0051 & 0.0158 & 0.0169 \\
0.0051 & 31.5180 & 0.0234 & 0.0248 \\
0.0158 & 0.0234 & 31.6033 & 0.0978 \\
0.0169 & 0.0248 & 0.0978 & 31.6153
\end{array}\right], \\
\mathbf{Q}_{11} & =\mathbf{Q}_{21} \\
& =\left[\begin{array}{cccc}
10.5037 & 0 & 0 & 0 \\
0 & 10.5037 & 0 & 0 \\
0 & 0 & 10.5037 & 0 \\
0 & 0 & 0 & 10.5037
\end{array}\right] .
\end{aligned}
$$

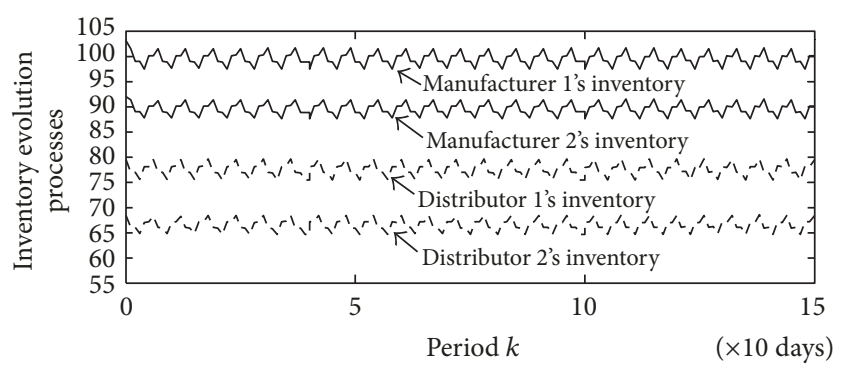

FIGURE 4: Inventory evolution processes under the common robust strategy $\left(\times 10^{4}\right.$ ton $)$.

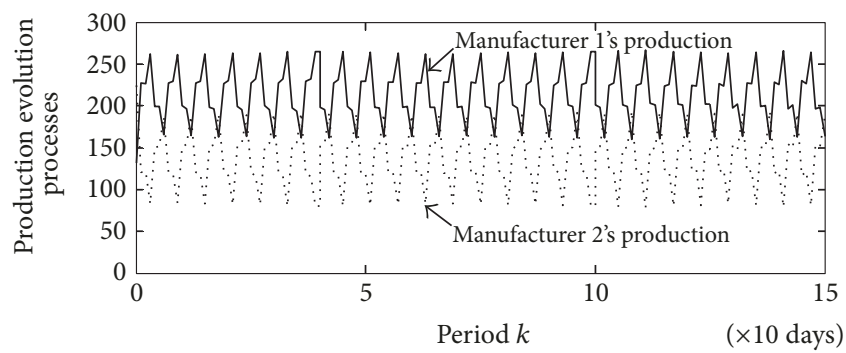

FIGURE 5: Production evolution processes under the common robust strategy $\left(\times 10^{4}\right.$ ton $)$.

Then, simulation experiments will be executed to compare the proposed fuzzy robust strategy with the common robust strategy for the inhibition effect on the lead times, the uncertain customer demand, and the fluctuation of the switching processes among subsystems of the supply chain network. Based on historical data, the initial values are set as $x_{1}(0)=2, x_{2}(0)=1.8, y_{1}(0)=1.5, y_{2}(0)=1.3\left(10^{5}\right.$ ton), and the normal values are set as $\vec{x}_{1}(k)=10.2, \vec{x}_{2}(k)=$ $10, \vec{y}_{1}(k)=9.8, \vec{y}_{2}(k)=9.5\left(10^{5}\right.$ ton $)$. Furthermore, the production lead times and the ordering lead times are both $\tau^{\prime}=\tau^{\prime \prime}=2(\times 10$ days $)$.

Suppose the customer demand follows the normal distribution disturbance; that is, $w_{1}(k)=w_{2}(k)=N\left(3,0.1^{2}\right)$. Figures 4-8 show the simulation results under the common robust strategy.

It can be seen from Figures $4-8$ that the inventory levels, the productions, the ordering quantities, and the total cost of the supply chain network all fluctuate drastically under the common robust strategy.

In the same simulation environment, the simulation experiments are executed under the fuzzy robust strategy proposed in this article, and the simulation results can be seen in Figures 9-12.

By using the fuzzy robust strategy proposed in Section 3.2, manufacturers and distributors can adjust their production and ordering according to the inventory levels by the flexible switching actions among subsystems. Compared with the common robust strategy, the disturbances caused by the switching actions among subsystems, the lead times, and the uncertain customer demand can be restrained effectively under the fuzzy robust strategy. Therefore, the total cost of the supply chain network can be maintained in the ideal level. It 


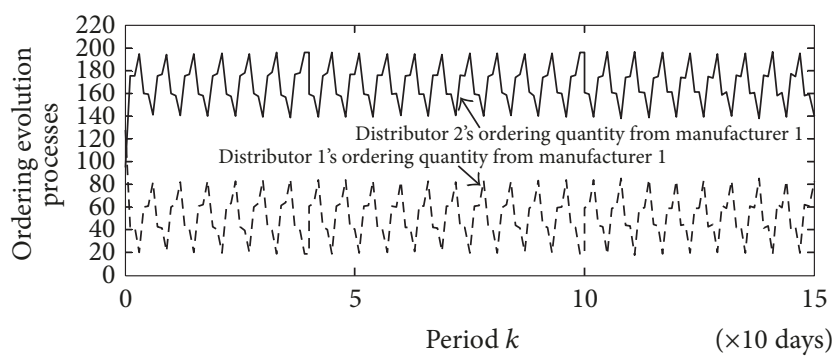

FIGURE 6: Ordering evolution processes from manufacturer 1 under the common robust strategy $\left(\times 10^{4}\right.$ ton $)$.

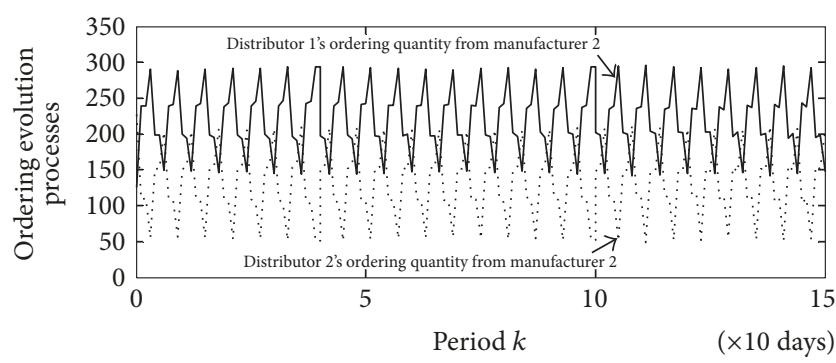

FIGURE 7: Ordering evolution processes from manufacturer 2 under the common robust strategy $\left(\times 10^{4}\right.$ ton $)$.

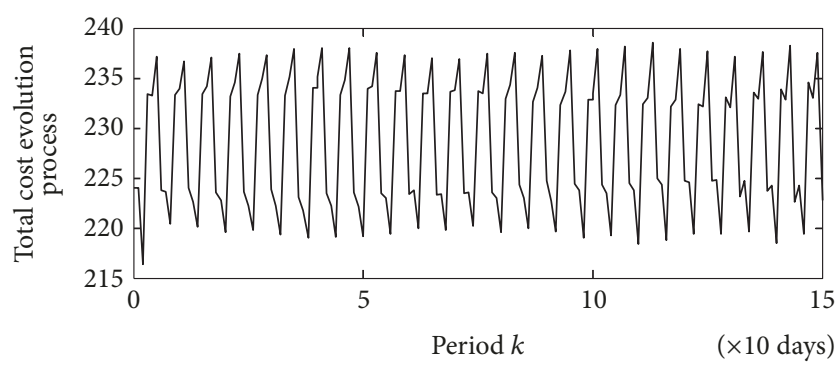

Figure 8: Total cost evolution process under the common robust strategy $\left(\times 10^{8} \mathrm{RMB}\right)$.

is clear that the fuzzy robust strategy proposed in this article can ensure that the supply chain network is robustly stable.

\section{Discussion}

(1) In Theorem 3, the robustly asymptotically stable supply chain network system (8) is derived from the following definition.

Definition 4 (see [29]). Given a scalar $\gamma>0$, the supply chain network system (8) is said to be robustly stable with the disturbance attenuation $\gamma$ if two conditions as below are satisfied: (1) The closed-loop system (8) is robustly asymptotically stable when $\mathbf{w}(k) \equiv 0$. (2) Under zero-initial condition, the controlled output $\mathbf{z}(k)$ satisfies $\|\mathbf{z}(k)\|_{2}^{2}<$ $\gamma\|\mathbf{w}(k)\|_{2}^{2}$ for any nonzero $\mathbf{w}(k) \in \ell_{2}[0, \infty)$ and all admissible uncertainties.

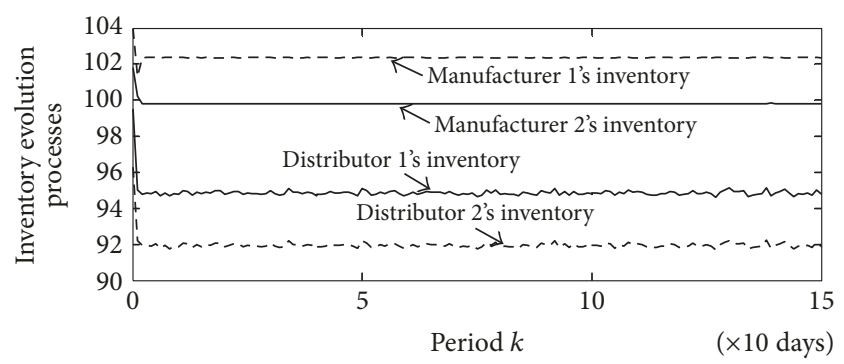

FIGURE 9: Inventory evolution processes under the fuzzy robust strategy $\left(\times 10^{4}\right.$ ton).

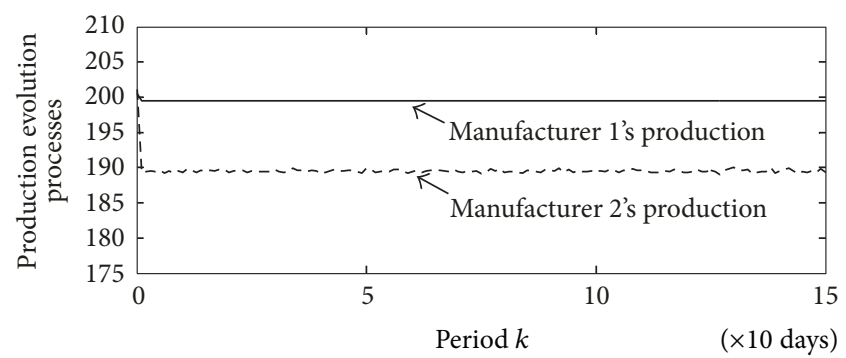

FIGURE 10: Production evolution processes under the fuzzy robust strategy $\left(\times 10^{4}\right.$ ton $)$.

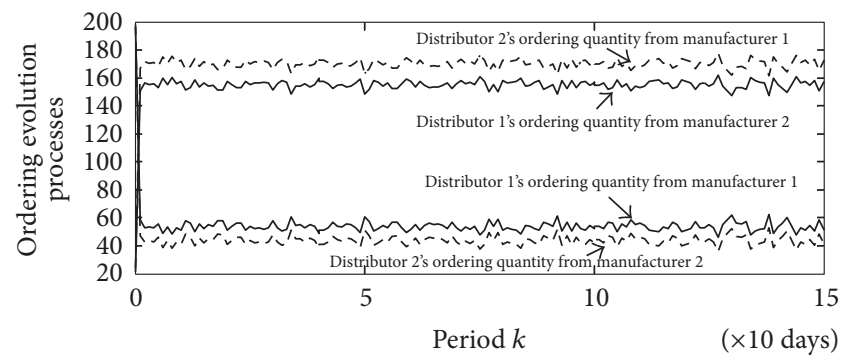

FIGURE 11: Ordering evolution processes under the fuzzy robust strategy $\left(\times 10^{4}\right.$ ton $)$.

The proof of Theorem 3 must satisfy the two conditions of Definition 4, and the similar detailed proof process can be seen in [28].

(2) Compared with the common robust strategy, the proposed fuzzy robust strategy can realize the flexible switching among subsystems of the supply chain network and effectively restrain the bullwhip effect. The bullwhip effect refers to the phenomenon of the amplification of demand variability from a downstream site to an upstream site in the supply chain [30]. The concept of bullwhip effect can describe the dynamic performance of our fuzzy robust controller.

\section{Conclusions}

In this article, we have studied the fuzzy robust control problem of dynamic supply chain network with the lead times and the uncertain demand. Taking into consideration the multiple sources of lead times in supply chain network, we focused on the production lead times and the ordering 


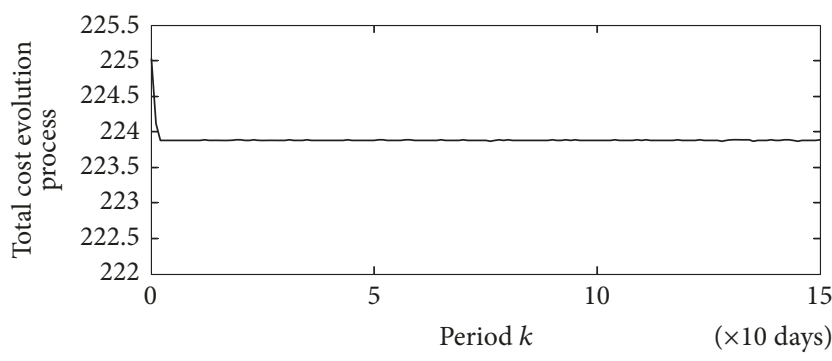

Figure 12: Total cost evolution process under the fuzzy robust strategy $\left(\times 10^{8} \mathrm{RMB}\right)$.

lead times. We first built a basic model for the discrete dynamic supply chain network with the lead times and the uncertain demand. By considering the safety inventory and the expected inventory, the constructed basic model is transformed into a fuzzy switched supply chain network model, and then we developed the fuzzy switched strategy composed of the manufacturers' production strategy and the distributors' ordering strategy to keep the ideal total operation cost of the supply chain network. From the perspective of control system, we explored a fuzzy control strategy to realize the robust stability of the discrete switched supply chain network with the uncertain customer demand and the lead times. Simulation study indicates the fuzzy membership function does play an important role in reducing the fluctuation of system variables. Simulation results also verify the effectiveness and applicability of the proposed fuzzy robust strategy composed of the fuzzy switched strategy and the fuzzy control strategy in improving the robustness of the supply chain network with respect to the uncertain demand and the lead times. In practice, our work provides a new approach for supply chain managers to design better robust control strategy and improve supply chain performance. In the future researches, the structured model can be extended to the new supply chain model with supply and demand not only among manufacturers but also among distributors. And another new strategy will be developed for the supply chain network with the uncertain system parameters and the timevarying lead times.

\section{Notations}

$x_{a}(k)$ : Manufacturer $a$ 's inventory at period $k$, $a=1,2, \ldots, s$

$y_{b}(k)$ : Distributor $b$ 's inventory at period $k$, $b=1,2, \ldots, t$

$u_{a}(k)$ : Manufacturer $a$ 's production at period $k$

$u_{a b}(k)$ : The ordering from distributor $b$ to manufacturer $a$ at period $k$

$w_{b}(k)$ : Distributor $b$ 's customer demand at period $k$

$\tau_{a}: \quad$ Lead time during the production

$\tau_{a b}: \quad$ Lead time during the ordering process

$R^{i}$ : The $i$ th fuzzy rule, $i=1,2, \ldots, r$

$r: \quad$ The number of IF-THEN rules

$M_{j}^{i}$ : The fuzzy set, $j=1,2, \ldots, n$ $z(k)$ : The total cost of the supply chain network at period $k$

$l_{a b}$ : The coefficient of supply and demand between manufacturer $a$ and distributor $b$

$c_{h a}:$ Manufacturer $a$ 's unit inventory cost

$c_{r b}$ : Distributor $b$ 's unit inventory cost

$c_{m a}:$ Manufacturer $a$ 's unit producing cost

$c_{o a b}$ : Distributor $b$ 's unit ordering cost from manufacturer $a$.

\section{Conflicts of Interest}

The authors declare that they have no conflicts of interest.

\section{Acknowledgments}

The authors are grateful for the support from the National Social Science Foundation of China (no. 17BGL222).

\section{References}

[1] M. S. Pishvaee and S. A. Torabi, "A possibilistic programming approach for closed-loop supply chain network design under uncertainty," Fuzzy Sets and Systems, vol. 161, no. 20, pp. 26682683, 2010 .

[2] M. S. Pishvaee, R. Z. Farahani, and W. Dullaert, "A memetic algorithm for bi-objective integrated forward/reverse logistics network design," Computers \& Operations Research, vol. 37, no. 6, pp. 1100-1112, 2010.

[3] M. S. Pishvaee, F. Jolai, and J. Razmi, "A stochastic optimization model for integrated forward/reverse logistics network design," Journal of Manufacturing Systems, vol. 28, no. 4, pp. 107-114, 2009.

[4] E. Mastrocinque, B. Yuce, A. Lambiase, and M. S. Packianather, "A multi-objective optimization for supply chain network using the bees algorithm," International Journal of Engineering Business Management, vol. 5, no. 1, pp. 1-11, 2013.

[5] T. Santoso, S. Ahmed, M. Goetschalckx, and A. Shapiro, "A stochastic programming approach for supply chain network design under uncertainty," European Journal of Operational Research, vol. 167, no. 1, pp. 96-115, 2005.

[6] A. Amiri, "Designing a distribution network in a supply chain system: formulation and efficient solution procedure," European Journal of Operational Research, vol. 171, no. 2, pp. 567-576, 2006.

[7] D. Ambrosino and M. G. Scutellà, "Distribution network design: new problems and related models," European Journal of Operational Research, vol. 165, no. 3, pp. 610-624, 2005.

[8] P. Seferlis and N. F. Giannelos, "A two-layered optimisationbased control strategy for multi-echelon supply chain networks," Computers \& Chemical Engineering, vol. 28, no. 5, pp. 799-809, 2004.

[9] J. Q. Xu, "Control of dynamic supply chain network," Chinese Journal of Management Science, vol. 15, no. 9, pp. 58-63, 2012 (Chinese), in Chinese.

[10] J. D. Schwartz, W. Wang, and D. E. Rivera, "Simulationbased optimization of process control policies for inventory management in supply chains," Automatica, vol. 42, no. 8, pp. 1311-1320, 2006. 
[11] E. R. Larsen, J. D. W. Morecroft, and J. S. Thomsen, "Complex behaviour in a production-distribution model," European Journal of Operational Research, vol. 119, no. 1, pp. 61-74, 1999.

[12] A. Almansoori and N. Shah, "Design and operation of a stochastic hydrogen supply chain network under demand uncertainty," International Journal of Hydrogen Energy, vol. 37, no. 5, pp. 3965-3977, 2012.

[13] M. Khatami, M. Mahootchi, and R. Z. Farahani, "Benders' decomposition for concurrent redesign of forward and closedloop supply chain network with demand and return uncertainties," Transportation Research Part E: Logistics and Transportation Review, vol. 79, pp. 1-21, 2015.

[14] K. Govindan and M. Fattahi, "Investigating risk and robustness measures for supply chain network design under demand uncertainty: a case study of glass supply chain," International Journal of Production Economics, vol. 183, pp. 680-699, 2017.

[15] N. Hamta, M. Akbarpour Shirazi, S. M. T. Fatemi Ghomi, and S. Behdad, "Supply chain network optimization considering assembly line balancing and demand uncertainty," International Journal of Production Research, vol. 53, no. 10, pp. 2970-2994, 2015.

[16] R. W. Salem and M. Haouari, "A simulation-optimisation approach for supply chain network design under supply and demand uncertainties," International Journal of Production Research, vol. 55, no. 7, pp. 1845-1861, 2017.

[17] N. Hamta, M. A. Shirazi, S. Behdad, and etal., "A novel bi-level stochastic programming model for supply chain network design with assembly line balancing under demand uncertainty," International Journal of Industrial and Systems Engineering, vol. 10, no. 2, pp. 87-112, 2017.

[18] A. Haddadsisakht and S. M. Ryan, "Closed-loop supply chain network design with multiple transportation modes under stochastic demand and uncertain carbon tax," International Journal of Production Economics, vol. 195, pp. 118-131, 2018.

[19] E. Eskigun, R. Uzsoy, P. V. Preckel, G. Beaujon, S. Krishnan, and J. D. Tew, "Outbound supply chain network design with mode selection and lead time considerations," Naval Research Logistics (NRL), vol. 54, no. 3, pp. 282-300, 2007.

[20] J.X. Xiao, Key-part based lead time management for the make-toorder production system in a global supply chain network [M.S.], Concordia University, 2007.

[21] X.-J. Han, A.-M. Feng, and B.-L. Zhang, "Approximate optimal inventory control of supply chain networks with lead time," in Proceedings of the 27th Chinese Control and Decision Conference, CCDC 2015, pp. 4523-4528, May 2015.

[22] C. Li and S. Liu, "A robust optimization approach to reduce the bullwhip effect of supply chains with vendor order placement lead time delays in an uncertain environment," Applied Mathematical Modelling, vol. 37, no. 3, pp. 707-718, 2013.

[23] M. Fattahi, K. Govindan, and E. Keyvanshokooh, "Responsive and resilient supply chain network design under operational and disruption risks with delivery lead-time sensitive customers," Transportation Research Part E: Logistics and Transportation Review, vol. 101, pp. 176-200, 2017.

[24] S. Zhang and X. Zhao, "Fuzzy robust control for an uncertain switched dual-channel closed-loop supply chain model," IEEE Transactions on Fuzzy Systems, vol. 23, no. 3, pp. 485-500, 2015.

[25] T. Takagi and M. Sugeno, "Fuzzy identification of systems and its applications to modeling and control," IEEE Transactions on Systems, Man, and Cybernetics, vol. 15, no. 1, pp. 116-132, 1985.
[26] E. Kim and H. Lee, "New approaches to relaxed quadratic stability condition of fuzzy control systems," IEEE Transactions on Fuzzy Systems, vol. 8, no. 5, pp. 523-534, 2000.

[27] Z.-H. Xiu and G. Ren, "Stability analysis and systematic design of Takagi-Sugeno fuzzy control systems," Fuzzy Sets and Systems, vol. 151, no. 1, pp. 119-138, 2005.

[28] S. Zhang, Y. Hou, and X. Zhao, "Robust stabilization for discrete uncertain Takagi-Sugeno fuzzy systems based on a piecewise Lyapunov function," Industrial \& Engineering Chemistry Research, vol. 53, no. 17, pp. 7132-7140, 2014.

[29] X. D. Liu and Q. L. Zhang, "Approaches to quadratic stability conditions and control designs for T-S fuzzy systems," IEEE Transactions on Fuzzy Systems, vol. 11, no. 6, pp. 830-839, 2003.

[30] H. L. Lee, V. Padmanabhan, and S. Whang, "Information distortion in a supply chain: the bullwhip effect," Management Science, vol. 43, no. 4, pp. 546-558, 1997. 


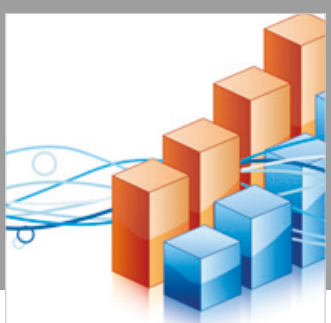

Advances in

Operations Research

\section{-n-m}
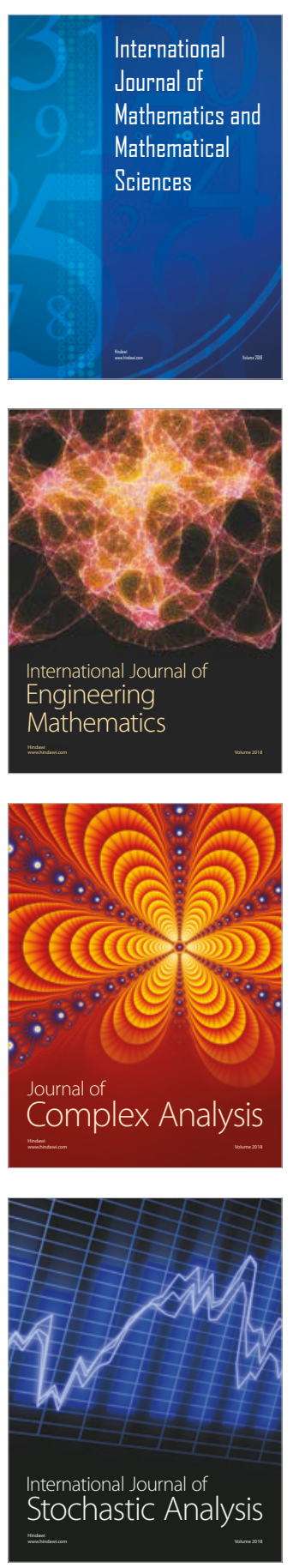
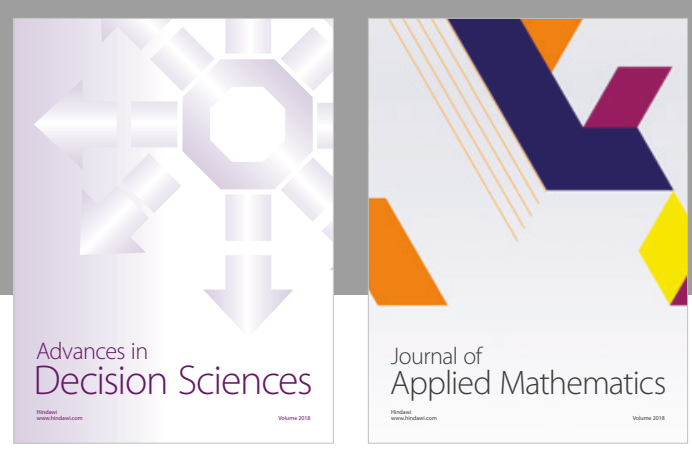

Journal of

Applied Mathematics
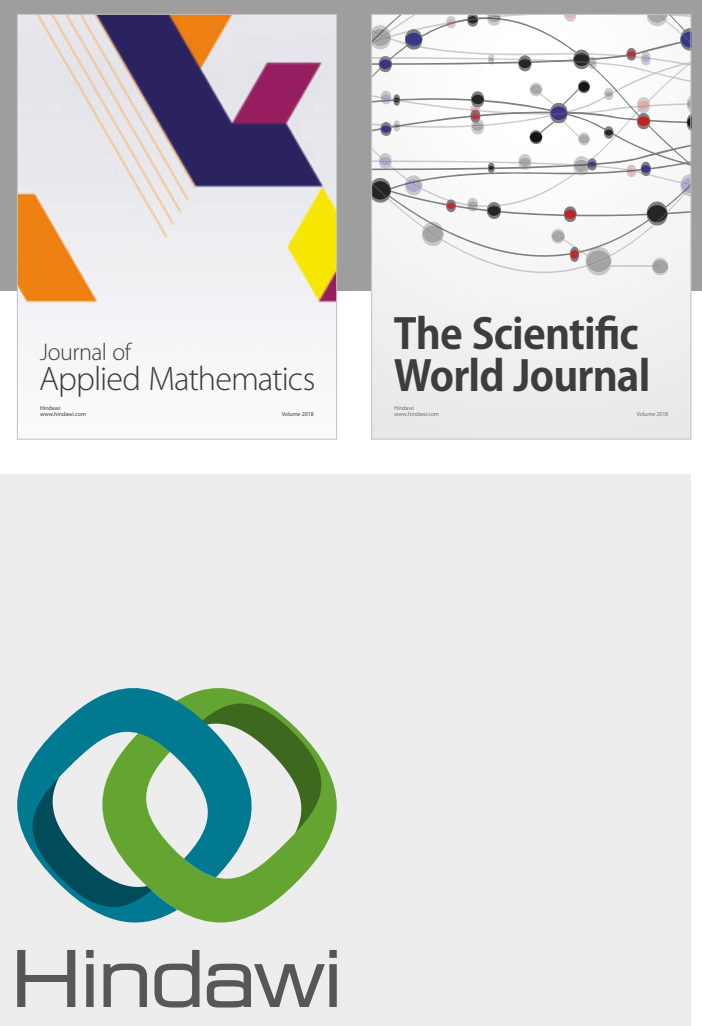

Submit your manuscripts at

www.hindawi.com

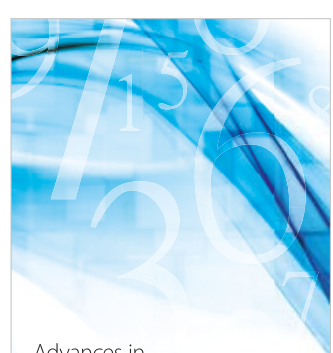

Advances in
Numerical Analysis
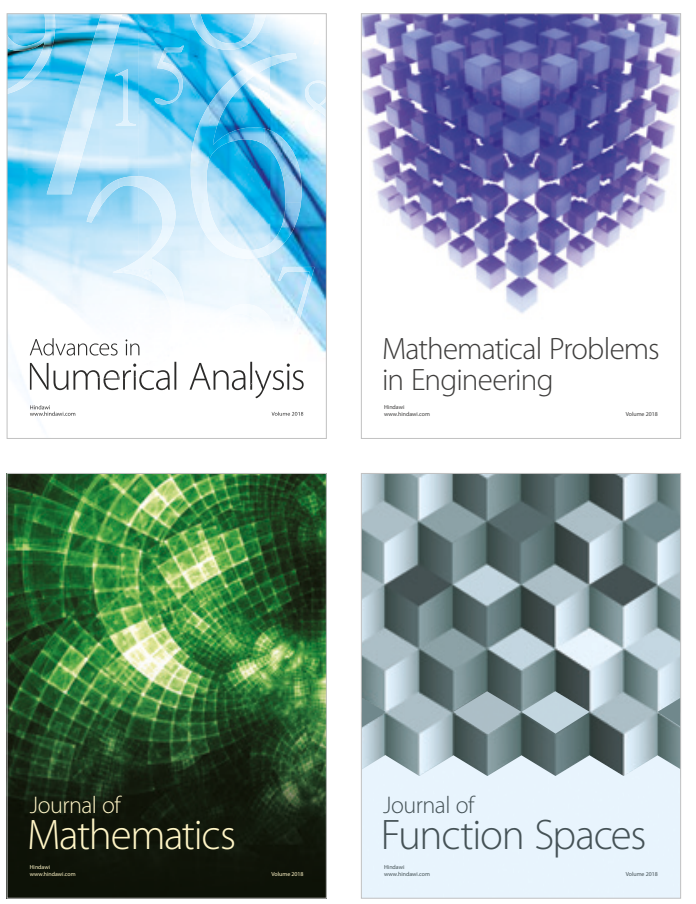

Mathematical Problems in Engineering

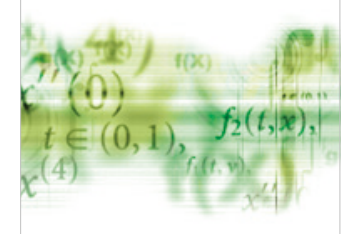

International Journal of

Differential Equations

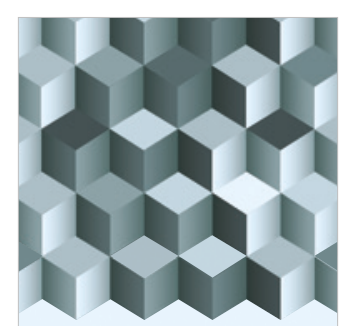

Journal of

Function Spaces
The Scientific

World Journal

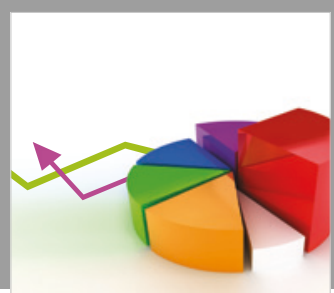

Journal of

Probability and Statistics
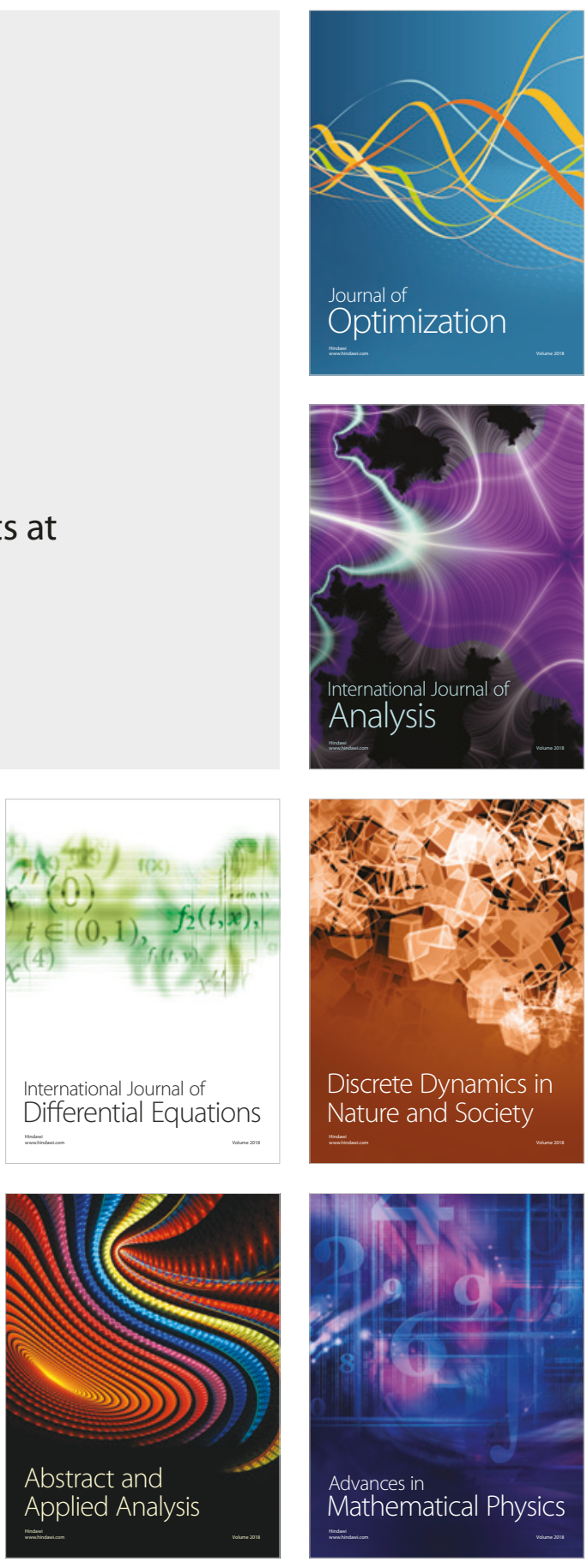